\title{
Perforating Wound of the Abdomen Through the Cervix Uteri: Suture : Recovery.
}

\author{
By A. N. McGregor, M.D., F.R.F.P.S.G.
}

THE following case is of interest on account of the rarity of the accident, the absence of other injuries, and the principal symptoms.

Mrs. D., æt. 49, was admitted to the Glasgow Royal Infirmary at midday on November 18 1909, complaining of severe bearing-down pains, the result of an accident which had occurred that morning.

The history of the accident is unusual. The patient seems to have been in the habit of using a long, hollow brass rod to assist her in arranging the bedclothes; the rod was three-eighths of an inch in diameter and $39 \frac{1}{2}$ inches long. When it was not in use it leant against the side of the bed. On the morning of the accident the patient was rising at 8 a.m., but she unfortunately got this rod between her legs, and when she slipped to the floor it penetrated her vagina to a considerable extent (as the anterior superior spine of the ilium was $32 \frac{1}{2}$ inches from the ground and the rod measured $39 \frac{1}{2}$ inches, more than 7 inches must have penetrated). She was wearing a short nightdress at the time, which was not, however, torn. After the accident she felt faint, but could step on to a chair; when she did so the rod fell from the vagina by its own weight. She then went back to bed. The only person present was an adopted daughter, aged $\boldsymbol{\tau}$, who immediately went off to get assistance; the patient's doctor was called in, and advised her removal to hospital. At the time of the accident there was a good deal of hæmorrhage, staining the bedclothes and mattress, and sufficient in quantity to fill a large bowl. Soon afterwards the pain commenced, which the patient described as typical labour pains.

There is little that is suggestive in the uterine history. She is married, and has had three children-two boys and one girl. The youngest was born 23 years ago, and after the parturition there was some inflammation of the womb and bladder.

On her admission, four hours after the accident, her temperature was $99.4^{\circ} \mathrm{F}$; her pulse, of good tension, numbered 120 beats per minute, and respirations 28 . There were no symptoms of internal hæmorrhage or collapse. The pains were very severe, and were "bearing down" in character; they came on at intervals of ten minutes, and their duration was about one minute. There was hrmorrhage from the vagina, but it was only an oozing, and was not influenced by the pains. She was anæsthetized by chloroform and a thorough examination made. There were no evidences whatever of 
bruising or laceration of the external genitalia, but a wound was found in the cervix uteri, about three-quarters of an inch in length; it began low down on the posterior lip and extended upwards and backwards. There was no protrusion of the abdominal contents through this wound, but the passage of the uterine sound revealed the fact that it was in direct continuity with the abdominal cavity. Traction was made on the cervix uteri by volsellum forceps, and the edges of the wound were brought together by a catgut suture. The vagina was then swabbed dry, and packed with iodoform gauze.

On the following day her temperature had risen to $100^{\circ} 4^{\circ} \mathrm{F}$. The pains were still severe, though less frequent, and there was some distension of the abdomen. The vaginal packing was renewed daily, till November 22, when the stitch was removed. The packing was not re-introduced, but douching was practised twice daily. The temperature was still running in the febrile register at this time, but on November 23 and following days defervescence took place, and at the same time the pains diminished in frequency, and finally ceased.

The patient made a rapid recovery, and on December 6 (18 days after the accident) she was dismissed-well. At that time the wound was quite healed; its site was marked by a little thickening of the posterior lip of the cervix.

She reported herself on January 261910 , and was then perfectly well.

In an article published in this JournaL in March 1907, I described a case of rupture of the vagina, which, in the absence of signs of bruising of the soft parts, and with a clear history of the occurrence, was believed to be a spontaneous rupture. The subject of this report is equally interesting, for, apart from the rarity of such an occurrence, there are two features of special importance. It would seem possible that the absence of bruising of the thigh, external genitalia and vagina would, in certain circumstances, be taken as presumptive evidence that the wounding instrument had been carefully introduced; and this might be used, in the absence of a definite history, as a differential point between criminal and accidental injuries. The clear history, the social condition of the patient--the wife of a respectable working man-and the production of the bloodstained rod, are satisfactory evidence that in this case the injury was purely accidental; and yet a careful examination under chloroform failed to reveal any other injury than the perforation of the cervix.

Apart from the hæmorrhage and some local tenderness, the prominent symptom was that of the rhythmic pains described as "labour pains," and continuing for some days. This symptom has not been previously observed or reported within my purview, and may be of some importance to those interested in the physiology of labour, and the point of origin of uterine contractions. 
In the absence of decided shock and signs of perforation of the bowel, it was not deemed advisable to explore the abdominal cavity, and the experience of the previous case (loc. cit.) of rupture of the vagina in which the bowel was returned into the pelvis appeared to warrant the course adopted, viz., that of suturing the opening in the cervix. The subsequent history showed that confidence to be well founded, and, although, the temperature remained somewhat high for over a week, and there was some tenderness in the lower abdomen, there never was any cause for anxiety, and the patient made a perfect recovery.

It should be noted that on the day after admission the patient was placed in a sitting posture, and lept in that decubitus for ten days. It is obvious that the instrument which penetrated into the peritoneal cavity was not surgically clean, and that reliance was placed on the power of the pelvic viscera to cope with the septic invasion. It may be noted also that no drain was used, as in the earlier case, and that suture of the tear in the cervix was necessary to stop hæmorrhage. It is difficult to estimate what length of the rod passed into the peritoneal cavity, for, although the measurements show that it was 7 inches longer than the distance from the floor to the anterior superior spine of the ileum, it is improbable that that amount of penetration occurred; the modifying factors would consist of the obliquity of direction of the rod, and the amount of upward displacement of the uterus before the cervical tissue gave way under the pressure of the blunt end of the rod. It is perfectly evident, however, in the absence of perforation of the bowel or even of intestinal hæmorrhage, that that structure was uninjured.

It is satisfactory to report the absence of complications and such sequelæ as might have arisen from the formation of adhesions. 